\title{
Circulating leptin, soluble leptin receptor, free leptin index, visfatin and selected leptin and leptin receptor gene polymorphisms in sporadic breast cancer
}

\author{
Chrishani Rodrigo ${ }^{1)}$, Kamani Hemamala Tennekoon ${ }^{1)}$, Eric Hamilton Karunanayake ${ }^{1)}$, \\ Kanishka De Silva ${ }^{2)}$, Indrani Amarasinghe ${ }^{2)}$ and Ananda Wijayasiri ${ }^{3)}$ \\ 1) Institute of Biochemistry, Molecular Biology and Biotechnology, University of Colombo, Colombo 03, 00300, Sri Lanka \\ 2) National Cancer Institute, Maharagama 10280, Sri Lanka \\ 3) Department of Community Medicine, Faculty of Medical Sciences, University of Sri Jayawardenapura, Nugegoda 10250, \\ Sri Lanka
}

\begin{abstract}
Leptin and visfatin are implicated in breast cancer risk but studies accounting for bioavailability of leptin are sparse. Reports on the association of leptin gene $(L E P)$ and leptin receptor gene (LEPR) polymorphisms with breast cancer are also inconsistent. Only a very few studies have examined biochemical and genetic variables concomitantly in the same cohort. A matched pairs study was carried out to ascertain whether plasma leptin, soluble leptin receptor, free leptin index (leptin/soluble leptin receptor), serum visfatin and selected $L E P$ and $L E P R$ polymorphisms are risk factors for sporadic breast cancer. Newly diagnosed sporadic breast cancer patients $(\mathrm{N}=80)$ were matched for age, body mass index $(\mathrm{BMI})$ and menopausal status with healthy controls. Plasma leptin, soluble leptin receptor and serum visfatin were measured by enzyme-immunoassay. $L E P-2548 \mathrm{~A} / \mathrm{G}$ and $L E P R \mathrm{~K} 109 \mathrm{R}, L E P R$ Q223R polymorphisms were determined by genotyping. Leptin $(p=0.0234)$, leptin/BMI $(p=0.0468)$, free leptin index $(p<0.0001)$ and visfatin $(p=0.0002)$ were significantly higher and soluble leptin receptor $(p<0.0001)$ was significantly lower in patients. LEPR gene K109R A/G polymorphism increased breast cancer risk (odds ratio: 4.125). Multivariate analysis confirmed that leptin, soluble leptin receptor, free leptin index and G109 (R109) allele of the LEPR gene K109R polymorphism are risk factors for breast cancer. When stratified by menopausal status free leptin index and soluble leptin receptor remained as risk factors irrespective of menopausal status while $L E P R$ gene $\mathrm{K} 109 \mathrm{R} \mathrm{A} / \mathrm{G}$ polymorphism remained as a risk factor only in the postmenopausal group.
\end{abstract}

Key words: Sporadic breast cancer, Leptin, Soluble leptin receptor, Visfatin, Leptin and leptin receptor gene polymorphism

BREAST CANCER is the commonest cancer and second leading cause of cancer death in women worldwide [1]. Currently it is the commonest cancer in Sri Lankan women with a cumulative incidence rate of $2.558 \%$ and age standardised incidence rate (ASR) of 23 per 100,000 women [2]. Multiple factors including genetic, hormonal and environmental factors are associated with breast cancer.

Obesity is a well-known risk factor for breast cancer [3]. In obesity adipokine secretion by the subcu-

Submitted Oct. 4, 2016; Accepted Dec. 5, 2016 as EJ16-0448 Released online in J-STAGE as advance publication Feb. 11, 2017 Correspondence to: Kamani Hemamala Tennekoon, Institute of Biochemistry, Molecular Biology and Biotechnology, University of Colombo, No: 90, Cumaratunga Munidasa Mawatha, Colombo 03, 00300, Sri Lanka. E-mail: kamani@ibmbb.cmb.ac.lk taneous and visceral adipose tissue is altered. Leptin mainly secreted by subcutaneous adipose tissue and visfatin secreted by visceral adipose tissue have been implicated in carcinogenesis including that of the breast $[4,5]$.

In human, leptin levels are proportionate to fat mass and play a role in mammary gland development and lactation [6]. Leptin exerts a greater proliferative effect in breast cancer cells than in normal mammary epithelial cells. It promotes cell proliferation, migration, and invasion, giving rise to more aggressive and metastatically more potent tumor cells [7]. Leptin exerts its effects through plasma membrane receptors which exist in several isoforms. Soluble leptin receptor (SLR) devoid of transmembrane and cytoplasmic domains has no signaling 
effect. SLR binds to circulating leptin and reduces its bioavailability. Hence both higher leptin levels and lower SLR levels cause a status of higher leptin action $[8,9]$.

Many studies reported higher leptin levels in breast cancer while lack of an association in a few studies was attributed to smaller numbers and concomitant pathologies [10-12]. A meta-analysis also confirmed a positive association of leptin with breast cancer [13]. Among breast cancer patients, obesity was associated with higher leptin levels than being overweight or normal weight [14]. Positive association of leptin and breast cancer was limited to post-menopausal women in some studies [15]. Despite many studies on leptin and breast cancer risk, possible association of SLR on breast cancer has not been adequately investigated. One study reported a negative association [16], but the effect was less than that of leptin.

Several $L E P$ and $L E P R$ gene polymorphisms have been studied in breast cancer patients in different populations. Of these, $L E P$ promoter $-2548 \mathrm{G} / \mathrm{A}$ (rs 7799039) and LEPR Q223R/Gln223Arg $\mathrm{A}>\mathrm{G}$ (rs1137101) and K109R/Lys109Arg A>G (rs1137100) polymorphisms were reported to increase risk and lead to poor prognosis of breast cancer in some but not in other studies [17-22]. Recent meta analyses showed that the LEP -2548 G/A and LEPR K109R but not the $L E P R$ Q223R polymorphism are associated with breast cancer [23-25]. Association of the polymorphisms with cancer also varied depending on the genetic model used, site of cancer, ethnicity of the subjects and the genotyping method.

Visfatin also known as nicotinamide phosphoribosyl transferase (nampt) is involved in angiogenesis, stress responses and cellular energy metabolism [26, 27]. An association of visfatin with a number of human malignancies including breast cancer has been reported but the association was limited to post-menopausal breast cancer in some studies $[5,15]$.

Although most studies have investigated the association of one or a few variables with breast cancer [11, 15], studies which looked concomitantly at circulating leptin, SLR and visfatin levels and $L E P$ or $L E P R$ SNPs are limited. Thus we measured circulating leptin, SLR and visfatin concentrations and determined LEP -2548 $\mathrm{G} / \mathrm{A}$, and LEPR K109R, Q223R polymorphisms in a matched pairs study to elucidate the relative contribution of these variables towards the risk of sporadic breast cancer.

\section{Materials and Methods}

\section{Study population}

Sporadic breast cancer patients and healthy controls of Sinhalese ethnicity matched for age ( \pm 5 years), BMI $( \pm 1)$ and menopausal status were studied in this matched pairs case-control study ( $\mathrm{N}=80$ pairs). Female patients with unilateral primary breast cancer were recruited from the National Cancer Institute Maharagama, Sri Lanka. None of them had a personal history of other cancers or a family history of any cancer. Furthermore, patients having diabetes mellitus, hypertension or dyslipidaemia were excluded from the study. Socio-demographic and clinical data were collected and height and weight recorded before surgery. Healthy females who did not have a personal or a family history of breast cancer or any other cancer and not having any other chronic disease such as diabetes mellitus, hypertension or dyslipidaemia, or an acute illness were selected from the community as matched controls. They were clinically free of breast pathology on admission to the study and remained so at 6 to 12 month follow up. Further they did not show any evidence of breast cancer on ultrasound examination at 6 to 12 month follow up.

Peripheral venous blood samples $(10 \mathrm{~mL})$ were obtained from patients before commencing chemotherapy or radiotherapy and from controls on admission to the study. Samples were obtained between $0900 \mathrm{~h}$ $1100 \mathrm{~h}$. Plasma, serum and cell pellets separated were stored at $-20^{\circ} \mathrm{C}$ or $-80^{\circ} \mathrm{C}$ as appropriate until measurement of leptin, SLR and visfatin or extraction of DNA for genotyping.

\section{Analysis of plasma leptin, SLR and serum visfatin levels}

Plasma leptin, SLR and serum visfatin levels were measured in duplicate using commercially available enzyme immunoassays [Human leptin (DRG Diagnostics, Germany, Catalogue number: EIA- 2395), human SLR (R \& D Systems, USA, Catalogue number: DOBR00), human visfatin (Antigenix America Inc. USA, Catalogue number: RHF783CKX)] according to manufacturers' instructions. Sensitivity and inter-assay and intra-assay coefficient of variations of these assays were within the expected range.

\section{Genotyping}

Genomic DNA extracted from cell pellets as described by Miller et al. [28] were amplified with 
target specific PCR primers designed in-house using the website 'Primer3: WWW primer tool' or obtained from published literature $[29,30]$. PCR primers used are given in Table 1.

For each of the primer pairs, PCR reaction mixture $(25 \mu \mathrm{L})$ consisted of 100 to $150 \mathrm{ng}$ genomic DNA, 3.5 $\mathrm{mmol} / \mathrm{L} \mathrm{MgCl}{ }_{2}, 1$ X PCR buffer [10 mM Tris- $\mathrm{HCl}(\mathrm{pH}$ 8.3) and $50 \mathrm{mM} \mathrm{KCl}$ ], $0.2 \mathrm{mmol} / \mathrm{L}$ dNTPs (Promega, Madison, WI, USA), $0.2 \mu \mathrm{M}$ of each primer and 1.5 units of Taq polymerases (Promega, USA). Thirty three cycles were performed in the thermal cycler (Applied Biosystems ${ }^{\circledR}$ Veriti ${ }^{\circledR} 96$ well thermal cycler-Life Technologies, USA), with initial denaturation at $94^{\circ} \mathrm{C}$ for 7 minutes, denaturation at $94^{\circ} \mathrm{C}$ for 1 minute, annealing at the respective optimum temperature (Table 1) for 1 minute and extension at $72^{\circ} \mathrm{C}$ for 2 minutes with final extension at $72^{\circ} \mathrm{C}$ for 10 minutes.

The amplified products were purified (Wizard $\AA$ SV Gel and PCR cleanup system; Promega, USA: Catalogue number: A9282) and quantified (Biospec Nanospectrometer; Shimadzu Cooperation, Model: A115746, Japan/USA). Purified PCR products were screened for respective SNPs by genotyping the polymorphic position using ABI PRISM ${ }^{\circledR}$ SNaPshot ${ }^{\mathrm{TM}}$ Multiplex Kit (Catalogue no: 4323159) and ABI 3500DX genetic analyzer (both from Applied Biosystems ${ }^{\circledR}$, Life Technologies, USA) according to the manufacturer's instructions. SNaPshot primers were designed in-house and suitability ascertained using Oligo Analyzer 3.1 (Integrated DNA Technologies, USA). Data were analysed with GeneMapper ${ }^{\circledR}$ v4.1 software (Applied Biosystems ${ }^{\circledR}$ ). Few representative samples were sequenced to confirm the SNPs identified by genotyping using BigDye ${ }^{\circledR}$ Terminator v3.1Cycle Sequencing Kit (Applied Biosystems $\left.{ }^{\circledR}\right)$ on ABI 3500DX genetic analyzer.

\section{Statistical analyses}

Prism 5.0 (Graph pad software Corporation, Inc, San Diego, California, USA) was used for data analysis. A two tailed probability value $<0.05$ was considered as statistically significant. Wilcoxon matched pairs test (leptin, SLR and visfatin levels) and the paired $t$ test [leptin/BMI and the free leptin index (FLI=leptin/SLR)] were used to compare cases and controls. Chi-squared test was used to ascertain whether allele and genotype frequencies were in Hardy-Weinberg equilibrium. McNemar's test was used to compare genotype distribution between cases and controls. Multivariate analysis was carried out using SPSS (Statistical Package for the Social Sciences: IBM SPSS Statistics 21.0, USA).

Cox regression as a method of conditional logistic regression, which preserves the matching of cases and controls, was used to estimate odds ratios (ORs) and 95\% confidence intervals (CIs) for the association of each variable with risk of cancer taking into account other variables. Homozygous wild type was considered as the non-risk group and, heterozygous and polymorphous homozygous genotypes together as the risk group (as they carry at least one variant allele) in determining the genotype contribution for breast cancer risk. Only the variables that showed a significant difference between cases and controls in the univariate analyses were used for this analysis. Two models were generated. First model included leptin, SLR, visfatin and G109 (R109) allele of LEPR gene K109R polymorphism. In the second model leptin and SLR were replaced by FLI and leptin/BMI. All analyses were carried out for the whole group and for pre-menopausal and post-menopausal pairs separately.

This study received ethical approval from the Institutional Review Board and all study participants gave written informed consent.

Table 1 PCR primers, annealing temperatures and expected product size

\begin{tabular}{|c|c|c|c|}
\hline SNP & Primer sequence & $\begin{array}{c}\text { Annealing } \\
\text { temperature } \\
\left({ }^{\circ} \mathrm{C}\right)\end{array}$ & $\begin{array}{l}\text { Product size } \\
\quad \text { (bps) }\end{array}$ \\
\hline$L E P$ gene $-2548 \mathrm{G} / \mathrm{A}$ & $\begin{array}{l}\mathrm{P}_{\mathrm{F}}: 5^{\prime} \text { TTTCTGTAATTTTCCCGTGAG 3' } \\
\mathrm{P}_{\mathrm{R}}: 5^{\prime} \text { AAAGCAAAGACAGGCATAAAAA 3' }\end{array}$ & 53.2 & 242 \\
\hline LEPR gene $\mathrm{Q} 223 \mathrm{R}$ & $\begin{array}{l}\mathrm{P}_{\mathrm{F}}: 5^{\prime} \text { CCCTTTAAGCTGGGTGTCCCAAATAG 3' } \\
\mathrm{P}_{\mathrm{R}}: 5^{\prime} \text { GCTAGCAAATATTTTGTAAGCAATT 3' }\end{array}$ & 62.3 & 416 \\
\hline LEPR gene $\mathrm{K} 109 \mathrm{R}$ & $\begin{array}{l}\mathrm{P}_{\mathrm{F}}: 5^{\prime} \text { TGCCTGCTGGACTCTCAAAG 3' } \\
\mathrm{P}_{\mathrm{R}}: 5^{\prime} \text { AGCTAATGCTTACCTATTTGTTAA 3' }\end{array}$ & 57.8 & 238 \\
\hline
\end{tabular}

$\mathrm{P}_{\mathrm{F}}$, Forward primer; $\mathrm{P}_{\mathrm{R}}$, Reverse primer. 


\section{Results}

Patients and controls were aged between 24-78 years (mean \pm SD: $48.69 \pm 11.40$ and $47.55 \pm 10.39$ years respectively). Forty two (52.5\%) of the matched pairs were pre-menopausal while $38(47.5 \%)$ were post-menopausal. Among the matched pairs, 3 pairs were underweight (BMI <18.5), 34 pairs were overweight (BMI 23.0 to 26.9), 18 pairs were obese $(\mathrm{BMI}>27)$ while the remaining 25 pairs were within the normal range for BMI (18.5 to 22.9). Biochemical variables in the patients and the controls are given in Table 2.

Patients had significantly higher FLI and visfatin concentrations, and significantly lower SLR concentrations than the controls irrespective of the menopausal status. Leptin and leptin/BMI were significantly higher in the whole group, but this difference was limited to post-menopausal women when analyzed by menopausal status.

Genotype and allele frequencies of the SNPs tested are shown in Table 3. GG (RR) genotype and the G (R) allele of $L E P R$ K109R SNP and GA genotype of LEP $-2548 \mathrm{G} / \mathrm{A}$ SNP showed a higher prevalence among the patients. Genotype and allele distributions of $L E P$ -2548 G/A and LEPR Q223R A/G were not in Hardy Weinberg Equilibrium. Only the LEPR K109R A/G polymorphism showed a significant association with breast cancer (Table 4), but the effect persisted only in post-menopausal women when analyzed by menopausal status.

In the conditional logistic regression analysis, chi square values of the overall score for the model were 29.335 and 33.996 for models 1 and 2 respectively, indicating the validity of the models. Leptin, SLR and the G109 (R109) genotype of LEPR K109R in model 1 and leptin/BMI, FLI and the G109 (R109) genotype in model 2 emerged as breast cancer risk factors (Table 5). Visfatin levels had no significant association in either model. Both SLR (model 1) and FLI (model 2) emerged as breast cancer risk factors for breast cancer in post-menopausal (Table 6) and pre-menopausal women (Table 7) upon stratification by menopausal status. However G109 (R109) genotype of LEPR K109R polymorphism emerged as a breast cancer risk factor only in post-menopausal women (Table 6).

Table 2 Biochemical variables in breast cancer patients and age and BMI matched controls

\begin{tabular}{|c|c|c|c|}
\hline Variable & Patients & Controls & $p$ value \\
\hline \multicolumn{4}{|l|}{ Leptin (ng/mL) } \\
\hline All $(\mathrm{N}=80)$ & $19.23(15.85,23.32)$ & $17.57(14.84,20.72)$ & 0.0234 \\
\hline Pre-menopausal $(\mathrm{N}=42)$ & $17.83(13.41,22.53)$ & $15.88(12.44,20.28)$ & 0.2994 \\
\hline Post-menopausal $(\mathrm{N}=38)$ & $21.49(16.00,28.87)$ & $18.51(14.78,23.20)$ & 0.0105 \\
\hline \multicolumn{4}{|l|}{ Leptin/BMI } \\
\hline All $(\mathrm{N}=80)$ & $1.65(0.085)$ & $0.89(0.067)$ & 0.0468 \\
\hline Pre-menopausal $(\mathrm{N}=42)$ & $0.98(0.108)$ & $0.89(0.103)$ & 0.4844 \\
\hline Post-menopausal ( $\mathrm{N}=38)$ & $1.16(0.133)$ & $0.88(0.085)$ & 0.0298 \\
\hline \multicolumn{4}{|l|}{ SLR (ng/mL) } \\
\hline All $(\mathrm{N}=80)$ & $16.27(15.04,17.61)$ & $21.14(19.37,23.08)$ & $<0.0001$ \\
\hline Pre-menopausal $(\mathrm{N}=42)$ & $16.10(14.48,17.91)$ & $21.26(18.52,24.41)$ & 0.0019 \\
\hline Post-menopausal $(\mathrm{N}=38)$ & $16.46(14.58,18.60)$ & $21.02(18.82,23.48)$ & 0.0134 \\
\hline \multicolumn{4}{|l|}{ Free leptin index } \\
\hline All $(\mathrm{N}=80)$ & $1.76(0.169)$ & $1.08(0.096)$ & $<0.0001$ \\
\hline Pre-menopausal $(\mathrm{N}=42)$ & $1.60(0.220)$ & $1.13(0.165)$ & 0.0086 \\
\hline Post-menopausal $(\mathrm{N}=38)$ & $1.944(0.259)$ & $1.024(0.086)$ & 0.0002 \\
\hline \multicolumn{4}{|l|}{ Visfatin (ng/mL) } \\
\hline All $(\mathrm{N}=80)$ & $0.35(0.26,0.47)$ & $0.14(0.09,0.20)$ & 0.0002 \\
\hline Pre-menopausal $(\mathrm{N}=42)$ & $0.35(0.22,0.56)$ & $0.16(0.09,0.27)$ & 0.0310 \\
\hline Post-menopausal $(\mathrm{N}=38)$ & $0.33(0.22,0.51)$ & $0.12(0.07,0.19)$ & 0.0032 \\
\hline
\end{tabular}

Data given are geometric mean (95\% confidence limits) for leptin, soluble leptin receptor (SLR) and visfatin and mean \pm SEM for leptin normalized to BMI (leptin/BMI) and free leptin index (leptin/SLR). Significant $p$ values are shown in bold. 
Table 3 Genotype and allele frequencies of LEPR gene K109R, Q223R polymorphisms and LEP gene $-2548 \mathrm{G} / \mathrm{A}$ polymorphism in patients and controls

\begin{tabular}{|c|c|c|c|c|c|c|}
\hline & \multicolumn{2}{|c|}{$\begin{array}{c}\text { All } \\
(\mathrm{N}=80 \text { pairs })\end{array}$} & \multicolumn{2}{|c|}{$\begin{array}{l}\text { Pre-menopausal } \\
(\mathrm{N}=42 \text { pairs })\end{array}$} & \multicolumn{2}{|c|}{$\begin{array}{l}\text { Post-menopausal } \\
(\mathrm{N}=38 \text { pairs })\end{array}$} \\
\hline & Patients & Controls & Patients & Controls & Patients & Controls \\
\hline \multicolumn{7}{|c|}{ LEPR gene: K109R A/G (Genotype and allele) } \\
\hline AA & 0.425 & 0.738 & 0.452 & 0.667 & 0.395 & 0.816 \\
\hline AG & 0.275 & 0.225 & 0.286 & 0.286 & 0.263 & 0.158 \\
\hline GG & 0.300 & 0.037 & 0.261 & 0.047 & 0.342 & 0.026 \\
\hline A & 0.562 & 0.850 & 0.595 & 0.810 & 0.526 & 0.895 \\
\hline G & 0.438 & 0.150 & 0.405 & 0.190 & 0.474 & 0.105 \\
\hline \multicolumn{7}{|c|}{ LEPR gene Q223R A/G (Genotype and allele) } \\
\hline AA & 0.813 & 0.750 & 0.762 & 0.667 & 0.868 & 0.842 \\
\hline AG & 0.112 & 0.075 & 0.119 & 0.119 & 0.106 & 0.026 \\
\hline GG & 0.075 & 0.175 & 0.119 & 0.214 & 0.026 & 0.132 \\
\hline A & 0.869 & 0.788 & 0.821 & 0.726 & 0.921 & 0.855 \\
\hline G & 0.131 & 0.212 & 0.179 & 0.274 & 0.079 & 0.145 \\
\hline \multicolumn{7}{|c|}{ LEP gene $-2548 \mathrm{G} / \mathrm{A}$ (Genotype and allele) } \\
\hline GG & 0.063 & 0.037 & 0.095 & 0.048 & 0.026 & 0.026 \\
\hline GA & 0.537 & 0.300 & 0.524 & 0.214 & 0.553 & 0.395 \\
\hline AA & 0.400 & 0.663 & 0.381 & 0.738 & 0.421 & 0.579 \\
\hline $\mathrm{G}$ & 0.331 & 0.188 & 0.357 & 0.155 & 0.303 & 0.224 \\
\hline A & 0.669 & 0.812 & 0.643 & 0.845 & 0.697 & 0.776 \\
\hline
\end{tabular}

Table 4 Genotype distribution between patients and controls as determined by McNemar's test

\begin{tabular}{lcccc}
\hline SNP & $\begin{array}{c}\text { Mc Nemar } \\
\chi^{2} \text { value }\end{array}$ & $p$ value & Odds ratio & 95\% CI \\
\hline LEPR gene K109R A/G & 14.049 & $\mathbf{0 . 0 0 0 2}$ & 4.125 & 1.87 to 10.34 \\
\hline All (N=80) & 3.048 & 0.0809 & 2.500 & 0.92 to 7.87 \\
\hline Pre-menopausal (N=42) & 11.250 & $\mathbf{0 . 0 0 0 8}$ & 9.00 & 2.16 to 79.98 \\
\hline Post-menopausal (N=38) & & & 0.615 & 0.22 to 1.60 \\
\hline LEPR gene Q223R A/G & 0.762 & 0.3827 & 0.222 & 0.02 to 1.07 \\
\hline All (N=80) & 3.273 & 0.0704 & 0.750 & 0.110 to 4.33 \\
\hline Pre-menopausal (N=42) & 0.001 & 1.000 & & \\
\hline Post-menopausal (N=38) & & & 0.500 & 0.05 to 3.49 \\
\hline LEP gene -2548 G/A & 0.167 & 0.6831 & 0.333 & 0.01 to 4.15 \\
\hline All (N=80) & 0.250 & 0.6171 & 1.000 & 0.13 to 78.50 \\
\hline Pre-menopausal (N=42) & 0.500 & 0.4795 & \\
\hline Post-menopausal (N=38) & & & & \\
\hline
\end{tabular}

CI, Confidence Interval; $p$, Probability. Significant $p$ values are shown in bold. 
Table 5 Conditional logistic regression using selected variables on the risk of breast cancer in 80 matched pairs

\begin{tabular}{lcccc}
\hline All & SE & Wald & $p$ value & Exp B (CI) \\
\hline Model 1 & & & & \\
Leptin level & 0.019 & 4.095 & $\mathbf{0 . 0 4 3}$ & $1.038(1.001$ to 1.077$)$ \\
SLR level & 0.040 & 9.475 & $\mathbf{0 . 0 0 2}$ & $0.885(0.818$ to 0.956$)$ \\
Visfatin level & 0.387 & 2.092 & 0.148 & $1.701(0.828$ to 3.493$)$ \\
G109 (R109) & 0.516 & 10.391 & $\mathbf{0 . 0 0 1}$ & $0.189(0.069$ to 0.521$)$ \\
\hline Model 2 & & & \\
Leptin/BMI & 0.883 & 5.760 & $\mathbf{0 . 0 1 6}$ & $0.120(0.021$ to 0.678$)$ \\
FLI & 0.754 & 10.033 & $\mathbf{0 . 0 0 2}$ & $10.90(2.486$ to 47.767$)$ \\
Visfatin level & 0.369 & 2.824 & 0.093 & $1.859(0.902$ to 3.829$)$ \\
G109 (R109) & 0.556 & 9.402 & $\mathbf{0 . 0 0 2}$ & $0.182(0.061$ to 0.541$)$ \\
\hline
\end{tabular}

CI, Confidence Interval; Exp B, Exponential Beta value; $p$, Probability; SE, Standard Error; Wald, Wald statistic value. Significant $p$ values are shown in bold.

Table 6 Conditional logistic regression using selected variables on the risk of breast cancer in 38 post- menopausal pairs

\begin{tabular}{llllc}
\hline Post-menopausal & SE & Wald & $p$ value & Exp B (CI) \\
\hline Model 1 & & & & \\
$\quad$ Leptin level & 0.035 & 2.251 & 0.134 & $1.053(0.984$ to 1.128$)$ \\
SLR level & 0.054 & 4.484 & $\mathbf{0 . 0 3 5}$ & $0.893(0.804$ to 0.992$)$ \\
Visfatin level & 0.530 & 0.761 & 0.383 & $1.588(0.562$ to 4.487$)$ \\
G109 (R109) & 0.929 & 6.966 & $\mathbf{0 . 0 0 8}$ & $0.086(0.014$ to 0.532$)$ \\
\hline Model 2 & & & \\
Leptin/BMI & 1.176 & 1.884 & 0.170 & $0.199(0.020$ to 1.995$)$ \\
FLI & 1.186 & 4.477 & $\mathbf{0 . 0 3 4}$ & $12.308(1.203$ to 12.588$)$ \\
Visfatin level & 0.562 & 0.327 & 0.567 & $1.379(0.459$ to 4.145$)$ \\
G109 (R109) & 0.974 & 6.136 & $\mathbf{0 . 0 1 3}$ & $0.090(0.013$ to 0.604$)$ \\
\hline
\end{tabular}

CI, Confidence Interval; Exp B, Exponential Beta value; $p$, Probability; SE, Standard Error; Wald, Wald statistic value. Significant $p$ values are shown in bold.

Table 7 Conditional logistic regression using selected variables on the risk of breast cancer in 42 pre- menopausal pairs

\begin{tabular}{lcccc}
\hline Pre-menopausal & SE & Wald & $p$ value & Exp B (CI) \\
\hline Model 1 & & & & \\
$\quad$ Leptin level & 0.024 & 2.693 & 0.101 & $1.039(0.993$ to 1.088$)$ \\
SLR level & 0.067 & 5.425 & $\mathbf{0 . 0 2 0}$ & $0.856(0.751$ to 0.976$)$ \\
Visfatin level & 0.584 & 1.150 & 0.284 & $1.871(0.595$ to 5.884$)$ \\
G109 (R109) & 0.664 & 2.715 & 0.099 & $0.335(0.091$ to 1.230$)$ \\
\hline Model 2 & & & \\
$\quad$ Leptin/BMI & 1.280 & 3.371 & 0.066 & $0.095(0.008$ to 1.172$)$ \\
FLI & 1.135 & 5.025 & $\mathbf{0 . 0 2 5}$ & $12.728(1.377$ to 17.684$)$ \\
Visfatin level & 0.566 & 2.504 & 0.114 & $2.448(0.808$ to 7.421$)$ \\
G109 (R109) & 0.745 & 3.151 & 0.076 & $0.266(0.062$ to 1.148$)$ \\
\hline
\end{tabular}

CI, Confidence Interval; Exp B, Exponential Beta value; $p$, Probability; SE, Standard Error; Wald, Wald statistic value. Significant $p$ values are shown in bold.

\section{Discussion}

Obesity is a well-known risk factor of breast cancer and several studies have shown this association is limited to post-menopausal women [31-33]. It is also associated with risk of second primary and contralateral breast cancer and poor survival. Leptin and visfatin are two molecules implicated in obesity mediated breast carcinogenesis. We investigated leptin, SLR and visfatin levels as well as one $L E P$ gene and two $L E P R$ gene polymorphisms in a matched pair study of sporadic breast cancer, using controls matched for age, BMI and menopausal state. Effect of each of these variables on breast cancer risk was examined while accounting for the other variables, using conditional logistic regression which preserves matched pairing. 
Patients had significantly higher leptin and lower SLR levels thus increasing biologically available leptin as reflected by significantly higher FLI. Higher leptin/BMI in patients indicates a higher leptin secretion by their adipocytes compared to controls. Visfatin used as a proxy for visceral fat [5] was also significantly higher among patients. When analyzed by menopausal status, leptin and leptin/BMI remained significantly higher only among post-menopausal women while the differences in SLR, FLI and visfatin were not affected by menopausal state. In the multivariate analysis leptin emerged as a significant risk factor for sporadic cancer in the whole group but not when stratified by menopausal status. Leptin's biological effect is modulated by SLR which sequesters circulating leptin. The only group which appears to have studied SLR in breast cancer previously, also observed lower SLR and higher FLI in the patients [16]. In our study, SLR and FLI emerged as risk factors for sporadic breast cancer even in the multivariate analysis irrespective of menopausal status. Positive association of visfatin with breast cancer was limited to post-menopausal women in some studies [15]. Despite our observation of significantly higher visfatin levels in both pre-menopausal and post-menopausal women, it failed to emerge as a risk factor in the multivariate analysis, when other factors were accounted for.

The three SNPs we examined have been widely studied in relation to breast cancer, with inconsistent results. Polymorphisms are likely to mediate breast cancer risk by their effects on leptin levels, leptin action or obesity. Q223R and K109R polymorphisms have failed to show any significant effect on obesity [34]. Further, these polymorphisms have shown inconsistent effects on leptin levels.

$L E P-2548 \mathrm{~A} / \mathrm{G}$ polymorphism, located in the $5^{\prime}$ region of the $L E P$ gene is implicated in transcription. A meta-analysis attributed breast cancer risk to the AA genotype [25], while in Ahvazian women, converse was true with GG genotype increasing breast cancer risk [35]. This polymorphism had no effect on breast cancer risk in our study. There are inconsistent reports on its effect on leptin levels with the AA genotype in Indians [36] and the G allele in Mexicans having higher leptin levels [37]. Despite a reduced leptin signaling implicated for the LEPR Q223R/Gln223Arg $\mathrm{A}>\mathrm{G}$ (rs1137101) [38] polymorphism, it has shown inconsistent results on breast cancer risk. Our results agree with the findings of a meta-analysis which did not find this polymorphism to be a risk factor [23]. Furthermore this polymorphism did not affect SLR levels in either the patients or the controls (data not shown) similar to studies from Iran on breast cancer [20], and population studies from Japan and Brazil $[39,40]$. However, in post menopausal women of European ancestry, this polymorphism was found to modulate SLR levels [41].

$L E P R$ K109R polymorphism was found to be a risk factor for breast cancer in a meta-analysis [24]. Our results further confirmed that the $\mathrm{G}$ allele coding for Arginine (R) increases breast cancer risk, but the effect was limited to post-menopausal women. A functional effect has not been reported for this polymorphism located in exon 4. Effect of this polymorphism on leptin levels is inconsistent with the $\mathrm{K}$ allele and the $\mathrm{R}$ allele reported to be associated with higher leptin levels in different studies [42-44]. We observed higher leptin levels in the G (R) allele, but the difference was statistically significant only among the controls (data not shown). Thus the risk of breast cancer conferred by this polymorphism does not appear to be mediated through leptin alone. SLR levels were also not affected by this polymorphism either in the patients or in the controls in the present study (data not shown). Reports from elsewhere on the association of this polymorphism with SLR is also inconsistent. Most studies did not find an association while a few studies reported an association where a modulating effect was seen in genome wide analysis among postmenopausal women of European ancestry and lower SLR levels in Korean premenopausal women with the $\mathrm{G}(\mathrm{R})$ allele [39-41, 45]. Although there is no reported functional effect or a consistent association with leptin levels or SLR levels, this allele emerged as a significant risk factor of sporadic breast cancer in the present study. It is plausible that the $G(R)$ allele is in linkage equilibrium with a yet unidentified factor predisposing to sporadic breast cancer particularly in postmenopausal women we studied.

Present study indicates that leptin, free leptin index, soluble leptin receptor, and $L E P R$ K109R polymorphism modulate risk of breast cancer independently of BMI. In post-menopausal women all these variables except leptin and in pre-menopausal women all these variables except leptin and LEPR K109R increased the risk of sporadic breast cancer, when other factors were taken into account. Our results also indicate that the 
free leptin index is likely to be a better predictor of breast cancer risk than circulating leptin levels.

\section{Acknowledgements}

Director and staff of the National Cancer Institute, Maharagama, Sri Lanka and all study participants are thanked for their cooperation, Dr. Geethanjali Senanayake, Consultant Radiologist for the radiological assessment of the controls and Prof. Kumudu Wijewardena for facilities for multivariate analyses.

\section{Funding}

This project supported by the National Research Council, Sri Lanka (Grant 11-018) awarded to KHT constituted part of the PhD studies of CR.

\section{Disclosure}

None of the authors have any potential conflicts of interest associated with this research.

\section{References}

1. Jemal A, Bray F, Center MM, Ferlay J, Ward E, et al. (2011) Global cancer statistics. CA Cancer J Clin 61: 69-90.

2. Cancer Incidence Data. Sri Lanka Year 2010. Cancer Registry, National Cancer Control Programme (2016) Ministry of Health \& Indigenous Medicine, Sri Lanka.

3. Loi S, Milne RL, Friedlander ML, McCredie MRE, Giles GG, et al. (2005) Obesity and outcomes in premenopausal and postmenopausal breast cancer. Cancer Epidemiol Biomarkers Prev 14: 1686-1691.

4. Garofalo C, Surmacz E (2006) Leptin and cancer. J Cell Physiol 207: 12-22.

5. Bi TQ, Che XM (2010) Nampt/PBEF/visfatin and cancer. Cancer Biol Ther 10: 119-125.

6. Neville MC, McFadden TB, Forsyth I (2002) Hormonal regulation of mammary differentiation and milk secretion. J Mammary Gland Biol Neoplasia 7: 49-66.

7. Cirillo D, Rachiglio AM, la Montagna R, Giordano A, Normanno N (2008) Leptin signaling in breast cancer: an overview. J Cell Biochem 105: 956-964.

8. Ahima RS, Osei SY (2004) Leptin signaling. Physiol Behav 81: 223-241.

9. Wallace AM (2000) Measurement of leptin and leptin binding in the human circulation. Ann Clin Biochem 37: 244-252.

10. Surmacz E (2007) Obesity hormone leptin: a new target in breast cancer. Breast Cancer Res 9: 301.

11. Gross AL, Newschaffer CJ, Hoffman-Bolton J, Rifai N, Visvanathan K (2013) Adipocytokines, inflammation, and breast cancer risk in postmenopausal women: a prospective study. Cancer Epidemiol Biomarkers Prev 22: 1319-1324.

12. Vona-Davis L, Rose DP (2007) Adipokines as endocrine, paracrine, and autocrine factors in breast cancer risk and progression. Endocr Relat Cancer 14: 189-206.

13. Niu J, Jiang L, Guo W, Shao L, Liu Y, et al. (2013) The Association between Leptin Level and Breast Cancer: A Meta-Analysis. PLoS One 8: e67349.
14. Babaei Z, Moslemi D, Parsian H, Khafri S, Pouramir M, et al. (2015) Relationship of obesity with serum concentrations of leptin, CRP and IL-6 in breast cancer survivors. J Egypt Natl Canc Inst 27: 223-229.

15. Assiri AM, Kamel HF, Hassanien MF (2015) Resistin, visfatin, adiponectin, and leptin: risk of breast cancer in pre- and postmenopausal Saudi females and their possible diagnostic and predictive implications as novel biomarkers. Dis Markers 2015: 253519.

16. Mohammadzadeh G, Ghaffari MA, Bafandeh A, Hosseini SM (2014) Association of serum soluble leptin receptor and leptin levels with breast cancer. $J$ Res Med Sci 19: 433-438.

17. Snoussi K, Strosberg AD, Bouaouina N, Ahmed BS, Helal AN, et al. (2006) Leptin and leptin receptor polymorphisms are associated with increased risk and poor prognosis of breast carcinoma. BMC Cancer 6: 38 .

18. Liu CL, Chang YC, Cheng SP, Chern SR, Yang TL, et al. (2007) The roles of serum leptin concentration and polymorphism in leptin receptor gene at codon 109 in breast cancer. Oncology 72: 75-81.

19. Cleveland RJ, Gammon MD, Long CM, Gaudet MM, Eng SM, et al. (2010) Common genetic variations in the LEP and LEPR genes, obesity and breast cancer incidence and survival. Breast Cancer Res Treat 120: 745-752.

20. Mohammadzadeh G, Ghaffari MA, Bafandeh A, Hosseini SM (2014) Effect of leptin receptor Q223R polymorphism on breast cancer risk. Iran J Basic Med Sci 17: 588-594.

21. Mahmoudi R, Alavicheh BN, Mozaffari MAN, Fararouei M, Nikseresht M (2015) Polymorphisms of Leptin (-2548 G/A) and Leptin Receptor (Q223R) Genes in Iranian Women with Breast Cancer. Int $J$ Genomics 2015: 132720.

22. Teras LR, Goodman M, Patel AV, Bouzyk M, Tang W, et al. (2009) No association between polymorphisms in LEP, LEPR, ADIPOQ, ADIPOR1, or ADIPOR2 and 
postmenopausal breast cancer risk. Cancer Epidemiol Biomarkers Prev 18: 2553-2557.

23. Liu P, Shi H, Liu R, Yang Y, Yang Y, et al. (2014) Lack of association between LEPR Q223R polymorphisms and cancer susceptibility: evidence from a meta-analysis. J BUON 19: 855-862.

24. Shi H, Shu H, Huang C, Gong J, Yang Y, et al. (2014) Association of LEPR K109R polymorphisms with cancer risk: a systematic review and pooled analysis. $J$ BUON 19: 847-854.

25. Liu Y, Wu H, Zhu Y, Gao Y (2015) Genetic association between leptin-2548G/A polymorphism and risk of cancer: a meta-analysis. Int J Clin Exp Med 8: 448-455.

26. Kim SR, Bae SK, Choi KS, Park SY, Jun HO, et al. (2007) Visfatin promotes angiogenesis by activation of extracellular signal-regulated kinase 1/2. Biochem Biophys Res Commun 357: 150-156.

27. Revollo JR, Körner A, Mills KF, Satoh A, Wang T, et al. (2007) Nampt/PBEF/Visfatin regulates insulin secretion in beta cells as a systemic NAD biosynthetic enzyme. Cell Metab 6: 363-375.

28. Miller SA, Dykes DD, Polesky HF (1998) A simple salting out procedure for extracting DNA from human nucleated cells. Nucleic Acids Res 16: 1215.

29. Untergasser A, Cutcutache I, Koressaar T, Ye J, Faircloth BC, et al. (2012) Primer3 - new capabilities and interfaces. Nucleic Acids Res 40: e115.

30. Sugathadasa BH, Tennekoon KH, Karunanayake EH, Kumarasiri JM, Wijesundere AP (2010) Association of $-2548 \mathrm{G} / \mathrm{A}$ polymorphism in the leptin gene with preeclampsia/pregnancy-induced hypertension. Hypertens Pregnancy 29: 366-374.

31. Carmichael AR (2006) Obesity as a risk factor for development and poor prognosis of breast cancer. BJOG 113: 1160-1166.

32. Druesne-Pecollo N, Touvier M, Barrandon E, Chan DS, Norat T, et al. (2012) Excess body weight and second primary cancer risk after breast cancer: a systematic review and meta-analysis of prospective studies. Breast Cancer Res Treat 135: 647-654.

33. Chan DS, Vieira AR, Aune D, Bandera EV, Greenwood $\mathrm{DC}$, et al. (2014) Body mass index and survival in women with breast cancer-systematic literature review and meta-analysis of 82 follow-up studies. Ann Oncol 25: 1901-1914.

34. Paracchini V, Pedotti P, Taioli E (2005) Genetics of leptin and obesity: a HuGE review. Am J Epidemiol 162: 101-114.

35. Mohammadzadeh G, Ghaffari MA, Bafandeh A, Hosseini SM, Ahmadi B (2015) The Relationship between -2548 G/A Leptin Gene Polymorphism and
Risk of Breast Cancer and Serum Leptin Levels in Ahvazian Women. Iran J Cancer Prev 8: 100-108.

36. Dasgupta S, Salman M, Siddalingaiah LB, Lakshmi GL, Xaviour D, et al. (2014) Genetic variants in leptin: Determinants of obesity and leptin levels in South Indian population. Adipocyte 4: 135-140.

37. Chavarria-Avila E, Mercado MV, Gomez-Bañuelos E, Ruiz-Quezada SL, Castro-Albarran J, et al. (2015) The Impact of LEP G-2548A and LEPR Gln223Arg Polymorphisms on Adiposity, Leptin, and LeptinReceptor Serum Levels in a Mexican Mestizo Population. Biomed Res Int 2015: 539408.

38. Yiannakouris N, Yannakoulia M, Melistas L, Chan JL, Klimis-Zacas D, et al. (2001) The Q223R polymorphism of the leptin receptor gene is significantly associated with obesity and predicts a small percentage of body weight and body composition variability. J Clin Endocrinol Metab 86: 4434-4439.

39. Ogawa T, Hirose H, Yamamoto Y, Nishikai K, Miyashita $\mathrm{K}$, et al. (2004) Relationships between serum soluble leptin receptor level and serum leptin and adiponectin levels, insulin resistance index, lipid profile, and leptin receptor gene polymorphisms in the Japanese population. Metabolism 53: 879-885.

40. Oliveira R, Cerda A, Genvigir FDV, Sampaio MF, Armaganijan D, et al. (2013) Leptin receptor gene polymorphisms are associated with adiposity and metabolic alterations in Brazilian individuals. Arq Bras Endocrinol Metab 57: 677-684.

41. Sun Q, Cornelis MC, Kraft P, Qi L, van Dam RM, et al. (2010) Genome-wide association study identifies polymorphisms in LEPR as determinants of plasma soluble leptin receptor levels. Hum Mol Genet 19: 1846-1855.

42. van Rossum CT, Hoebee B, van Baak MA, Mars M, Saris WH, et al. (2003) Genetic variation in the leptin receptor gene, leptin, and weight gain in young Dutch adults. Obes Res 11: 377-386.

43. Wauters M, Mertens I, Chagnon M, Rankinen T, Considine RV, et al. (2001) Polymorphisms in the leptin receptor gene, body composition and fat distribution in overweight and obese women. Int J Obes Relat Metab Disord 25: 714-720.

44. Fan SH, Say YH (2014) Leptin and leptin receptor gene polymorphisms and their association with plasma leptin levels and obesity in a multi-ethnic Malaysian suburban population. J Physiol Anthropol 33: 15.

45. Kim SM, Kim SH, Lee JR, Jee BC, Ku SY, et al. (2008) Association of leptin receptor polymorphisms Lys109Arg and Gln223Arg with serum leptin profile and bone mineral density in Korean women. Am J Obstet Gynecol 198: 421.e1-421.e8. 